\title{
Values in family businesses owned by Chinese diaspora in Sarawak, Malaysia
}

\author{
Su-Hie Ting \\ Faculty of Language and Communication, \\ Universiti Malaysia Sarawak, \\ 94300 Kota Samarahan, Sarawak, Malaysia \\ Email: suhieting@gmail.com
}

\begin{abstract}
The case study aimed to describe the values in family businesses owned by Chinese diaspora in Sarawak, Malaysia. Interviews were conducted with founders and successors from 12 Chinese family businesses to identify the values. Of the 26 values identified, the most common values are trustworthiness, hard work and prioritising personal interest over family obligation. Prioritising personal interest over family obligation, discipline and being daring in business are new values which emerged in this study, and suggest a move away from traditional values. Apart from these, it seems that Chinese cultural values are largely maintained in this Malaysian Chinese diaspora despite the prolonged contact with host cultures and the Western educational background of successors. The study produced a framework for prevailing values in family businesses owned by Chinese diaspora in Malaysia which is firmly anchored to an established framework of Chinese cultural values.
\end{abstract}

Keywords: values; family business; Chinese cultural values; diaspora; Malaysia.

Reference to this paper should be made as follows: Ting, S-H. (xxxx) 'Values in family businesses owned by Chinese diaspora in Sarawak, Malaysia', Int. J. Chinese Culture and Management, Vol. X, No. Y, pp.xxx-xxx.

Biographical notes: Su-Hie Ting is an Associate Professor at the Universiti Malaysia Sarawak, Faculty of Language and Communication. She is the author of Chinese Family Business in Sarawak: Life Stories in published by Universiti Malaysia Sarawak Publisher as well as many journal papers on language choice and identity, and disease risk communication.

\section{Introduction}

In family business studies, values have been of interest because they are often seen as providing idiosyncratic resources and tacit knowledge to ensure continuity of the family business past the third generation (Duh et al., 2009; Kets de Vries, 1993; Morris et al., 1996; Poza, 2010; Ward, 1987). For a family business, the values that prevail in the business are often the personal values of the founder because the family and the business are inseparable.

In the context of Chinese diaspora who own family businesses all over the world, one question which arises is whether they retain Chinese values from China despite living 